Jurnal Media

Teknik dan

Sistem Industri e-issn: 2581-0561

p-issn: 2581-0529

DOI : $10.35194 /$ jmtsi.v5i1.1386

\title{
Tinjauan Kapasitas Persediaan Produk Fuji Seat PT. Tri Jaya Teknik Karawang
}

\author{
Aries Adiyanto $^{1 *}$, Dene Herwanto ${ }^{2}$ \\ ${ }_{1,2}$ Teknik Industri Universitas Singaperbangsa Karawang \\ Jl. HS Ronggo Waluyo, Teluk Jambe Timur, Karawang, Jawa Barat, Indonesia 41361 \\ 1*aries.adiyanto17018@student.unsika.ac.id \\ 22dene.herwanto@ft.unsika.ac.id
}

\section{Review Of The Capacity Of The Inventory Of Fuji Seat Products Tri Jaya Teknik Karawang, Ltd.}

Dikirimkan: 03, 2021. Diterima: 03, 2021. Dipublikasikan : 03, 2021.

\begin{abstract}
PT. Tri Jaya Teknik Karawang is an engineering company engaged in fabrication, machining and side parts. PT. Tri Jaya Teknik started pioneering a business since 2007 and started owning and occupying its own workshop in 2009. Currently the company already has 2 plant workshops with a total area of 3,080 $\mathrm{m}^{2}$ and has about 100 employees. One of the products produced is Fuji seat, based on the data collected there are 3 parts of the process. The 3 parts of the process are repair 1, repair 2, repair 3 . With each there is a check parts \& packing table. The method used in companies to manage raw material inventories is still conventional, namely by making continuous purchases without estimating according to needs. So that there is often an excess of raw materials or a shortage of raw materials at a certain time, this makes the costs incurred inefficient and often disrupts the production process. A review of the inventory capacity of Fuji Seat products in this study was carried out using the Economic Order Quantity (EOQ) model. The main raw material inventory data used is Fuji Seat in the 2016-2019 period. Holding cost raw materials is set by PT. Tri Jaya Teknik Karawang is $2.5 \%$ of the price per pcs, this value is used for procurement and repair of tools and equipment in the warehouse. If there is no damage, the cost is allocated to the warehouse manager in that month. Meanwhile, the cost of ordering which consists of the price of goods and shipping costs is determined by PT. Tri Jaya Teknik Karawang, amounting to IDR 100,000.00. This fee includes administration and transportation costs. Administrative costs, namely executive salaries and other supporters, as well as taxes related to the company. The cost of shipping transport is the distance traveled and the weight of the product ordered. Based on the calculation of EOQ (Economic Order Quantity), the most economical amount of raw materials using the EOQ model is 6,815.5 Pcs with 187 purchases a year.
\end{abstract}

Keywords - Fuji Seat, Economic Order Point, Inventory Capacity.

\begin{abstract}
Abstrak- PT. Tri Jaya Teknik Karawang adalah perusahaan engineering yang bergerak di bidang fabrikasi, machining dan part samping. PT. Tri Jaya Teknik mulai merintis bisnis sejak tahun 2007 dan mulai memiliki dan menempati workshop sendiri di tahun 2009. Saat ini perusahaan telah memiliki 2 plant workshop dengan total luas $3.080 \mathrm{~m}^{2}$ dan memiliki karyawan berjumlah sekitar 100 orang. Salah satu produk yang dihasilkan adalah fuji seat, berdasarkan data yang dikumpulkan ada 3 bagian proses. 3 bagian proses itu adalah repair 1, repair 2 , repair 3 . Dengan masing-masing terdapat meja check part \& packing. Metode yang digunakan pada perusahaan untuk mengelola persediaan bahan baku masih secara konvensional, yaitu dengan melakukan pembelian terus menerus tanpa memperkirakan sesuai dengan kebutuhan. Sehingga sering kali terjadi kelebihan bahan baku atau kekurangan bahan baku di saat tertentu, hal ini membuat biaya yang dikeluarkan menjadi tidak efisien dan sering kali mengganggu proses produksi. Tujuan penelitian ini yaitu mampu mengetahui perhitungan EOQ dan frekuensi pembelian yang paling ekonomis dalam perusahaan. Tinjauan kapasitas persediaan produk Fuji Seat dalam penelitian ini dilakukan dengan menggunakan model Economic Order Quantity (EOQ). Data persediaan bahan baku utama yang digunakan adalah Fuji Seat pada periode 2016-2019. Biaya penyimpanan bahan baku di tetapkan oleh pihak PT. Tri Jaya Teknik Karawang sebesar 2,5\% dari harga per pcs, nilai tersebut digunakan untuk keperluan pengadaan dan perbaikan
\end{abstract}


alat serta perlengkapan di gudang penyimpanan. Apabila tidak terjadi kerusakan maka biaya tersebut dialokasikan ke pengelola gudang dalam bulan tersebut. Sedangkan biaya pemesanan yang terdiri dari harga barang dan biaya pengiriman ditetapkan pihak PT. Tri Jaya Teknik Karawang sebesar Rp 100.000,00. Biaya ini meliputi biaya administrasi dan transportasi. Biaya administrasi yaitu gaji eksekutif dan pendukung lainnya,serta pajak yang berkaitan dengan perusahaan. Biaya transportasi pengiriman yaitu jarak yang ditempuh serta berat produk yang dipesan. Berdasarkan perhitungan EOQ (Economic Order Quantity) jumlah bahan baku yang paling ekonomis dengan menggunakan model EOQ didapat sebesar 6.815,5 Pcs dengan pembelian sebanyak 187 kali dalam satu tahun.

Kata kunci-Fuji Seat, Economic Order Point, Kapasitas Persediaan.

\section{PENDAHULUAN}

Kemajuan di era globalisasi ini, manusia didorong untuk semakin inovatif dalam menjalankan usaha. Persaingan yang semakin ketat membuat seseorang harus lebih teliti dalam memanfaatkan peluang usaha dengan tujuan untuk mendapatkan keuntungan yang optimal. Salah satu cara yang dilakukan adalah pengendalian persediaan yang optimal agar dapat mengefisiensi biaya yang dikeluarkan perusahaan dalam penyimpanan bahan baku. Namun, dalam prosesnya perusahaan akan dihadapkan dengan situasi mengenai keputusan pengendalian persediaan [1].

Faktor utama yang menunjang kelancaran dan efektifitas proses produksi dalam usaha menciptakan keuntungan perusahaan adalah bahan baku. Kegagalan pengendalian persediaan bahan baku akan menyebabkan kegagalan dalam memperoleh laba perusahaan [2].

Pengendalian merupakan upaya dari manajemen untuk mencapai tujuan yang telah di rencanakan. Pengendalian dalam perusahaan sangat penting karena akan mempengaruhi kelancaran operasional yang secara tidak langsung juga berpengaruh terhadap keberhasilan perusahaan tersebut. Sistem pengendalian dalam kegiatan produksi adalah pengendalian proses produksi, pengendalian persediaan bahan baku, pengendalian tenaga kerja, pengendalian biaya produksi, pengendalian kualitas serta pemeliharaan[3].

Ada tiga bentuk utama dari persediaan perusahaan yaitu persediaan bahan mentah, bahan dalam proses dan barang jadi. Untuk menjamin ketersediaan setiap persediaan tersebut dibutuhkan pengendalian yang efisien, karena persediaan ini akan berdampak pada biaya yang dikeluarkan perusahaan dan penghematan biaya akan berdampak pada harga jual. Oleh sebab itu, agar biaya produksi dan nilai perusahaan tetap terjaga maka perusahaan harus mencari strategi yang tepat agar biaya produksi menjadi optimal[4].

Persediaan bahan baku memiliki pengaruh signifikan terhadap proses produksi. Perusahaan yang bergerak di bidang industri, sering mengalami kendala di dalam menjalankan suatu kegiatan produksinya, kendala tersebut di antaranya adalah mengenai besar kecilnya suatu persediaan bahan baku pembantu yang ada di perusahaan. Oleh karena itu, diperlukan pengendalian persediaan bahan baku pembantu untuk mengantisipasi kendala tersebut. Pengendalian persediaan bertujuan agar barang jadi dapat sessuai dengan yang diinginkan oleh pelanggaan [5]

Persediaan yang optimal dapat dicapai apabila dapat menyeimbangkan antara beberapa faktor mengenai kuantitas produk, daya tahan produk, panjangnya periode produksi, fasilitas penyimpanan dan biaya penyimpanan, kecukupan modal, kebutuhan waktu distribusi, perlindungan mengenai kekurangan tenaga kerja, perlindungan mengenai kekurangan harga bahan dan perlengkapan serta risiko yang ada dalam perusahaan [6].

Ada beberapa sistem pengendalian bahan baku yaitu EOQ (Economic Order Quantity), sistem $\mathrm{ABC}$, dan just in time. EOQ berusaha menghitung tingkat persediaan yang optimal, sistem ABC mengklarifikasi item-item persediaan menurut jumlah dan prioritasnya, sedangkan just in time bertujuan meminimalkan tingkat persediaan, kalau bisa tingkat persediaan ditekan menjadi nol [6].

EOQ sebenarnya merupakan volume atau jumlah pembelian yang paling ekonomis untuk dilaksanakan pada setiap kali pembelian. Untuk memenuhi kebutuhan itu maka dapat diperhitungkan pemenuhan kebutuhan (pembeliannya) yang paling ekonomis yaitu sejumlah barang yang akan dapat diperoleh dengan pembelian dengan menggunakan biaya yang minimal [7].

Salah satu model yang sering digunakan untuk mengetahui jumlah persediaan bahan baku adalah model EOQ (Economic Order Quantity). Metode ini sering dipakai karena mudah untuk dilaksanakan dan dapat memberikan solusi terbaik bagi perusahaan, karena dengan menggunakan EOQ tidak hanya mengetahui berapa jumlah persediaan yang paling efisien, tetapi juga dapat mengetahui biaya yang dikeluarkan dengan persediaan yang dimiliki (Total Inventory Cost) serta waktu yang paling tepat untuk melakukan pemesanan kembali (Reorder Point) [8].

Salah satu pengendalian yang penting adalah pengendalian persediaan bahan baku karena persediaan ini merupakan unsur paling aktif dalam operasi perusahaan yang secara terus menerus diubah, diperoleh yang kemudian dijual kembali [9].

ROP atau Re Order Point merupakan titik di mana harus diadakan pesanan lagi sedemikian rupa sehingga kedatangan atau penerimaan material yang dipesan adalah tepat pada waktu di mana persediaan di atas safety stock [9]. 
Model EOQ ini tidak hanya dapat menentukan jumlah pemesanan yang optimal tetapi juga menyangkut aspek finansial dari keputusankeputusan tentang kuantitas pesanan tersebut. Apabila perusahaan sudah menghitung kuantitas pemesanan yang paling optimal atau EOQ, selanjutnya harus ditentukan jumlah pemesanan pada masing-masing item persediaan atau biasa disebut dengan Re Order Point [10].

. Persediaan pengaman atau Safety Stock adalah suatu jumlah persediaan minimum yang selalu ada dalam perusahaan, yang berguna untuk menghindari risiko kehabisan bahan [10].

. Berdasarkan uraian di atas, peneliti memilih menggunakan EOQ karena perusahaan yang diteliti tidak banyak jenis persediaannya, selain itu, perusahaan yang diteliti belum besar perkembangannya sehingga lebih cocok menggunakan model EOQ yang lebih sederhana.

PT. Tri Jaya Teknik Karawang merupakan perusahaan engineering yang bergerak di bidang fabrikasi, machining, dan part stamping, yang berada di Jl. Alternatif Krajan II Ds. Warung Bambu Kec. Karawang Timur. Salah satu produk yang dihasilkan di PT. Tri Jaya Teknik Karawang adalah produk fuji seat yang merupakan produk baru untuk customer pada tahun ini.

Metode yang digunakan pada perusahaan untuk mengelola persediaan bahan baku masih secara konvensional, yaitu dengan melakukan pembelian terus menerus tanpa memperkirakan sesuai dengan kebutuhan. Sehingga terjadi kelebihan bahan baku atau kekurangan bahan baku di saat tertentu, hal ini membuat biaya yang dikeluarkan menjadi tidak efisien dan mengganggu proses produksi. Oleh karena itu penelitian ini bertujuan untuk mengetahui perhitungan EOQ dan frekuensi pembelian yang paling ekonomis dalam perusahaan.

\section{Metodologi Penelitian}

Penelitian ini dilakukan dengan studi literatur dan studi lapangan. Studi literatur dilakukan dengan mencari sumber - sumber teori yang sudah ada, sementara studi lapangan dilakukan dengan survei langsung ke perusahaan, wawancara di bagian PPIC dan dokumentasi di bagian produksi fuji seat.

Objek yang diteliti adalah mengenai kapasitas persediaan yang berfungsi mengatur persediaan barang yang dimiliki. Mulai dari memperoleh persediaan penyimpanan, sampai barang dikeluarkan. PT. Tri Jaya Teknik Karawang hanya melakukan pencatatan pembelian pada order yang besar saja seperti pembelian dari luar kota atau pusat kota, sedangkan untuk pembelian-pembelian kecil yang dilakukan langsung di pabrik tidak dilakukan pencatatan secara rinci.

Adapun tahapan yang dilakukan pada penelitian ini, diantaranya:

1. Pengumpulan data

Data yang diperlukan dalam penelitian ini adalah data pemakaian bahan baku fuji seat (logam), harga bahan baku dan biaya bahan baku.

2. Pengolahan data

Beberapa data yang didapatkan selanjutnya diolah menggunakan metode yang sesuai dalam penelitian ini.

3. Penggunaan metode Economic Order Quantity Metode ini akan mengusulkan tentang frekuensi pembelian paling ekonomis produk fuji seat (logam) dalam satu tahun.

Perhitungan Economic Order Quantity (EOQ) dapat diformulasikan sebagai berikut:

$$
\mathrm{EOQ}=\sqrt{ } \frac{2 . R . S}{P . I}
$$

Keterangan :

$\mathrm{R}=$ Kuantitas yang diperlukan selama periode tertentu.

$\mathrm{S}=$ biaya pemesanan setiap kali pesan disebut dengan ordering cost/setup cost.

$\mathrm{P}=$ harga bahan per unit.

I =biaya penyimpanan bahan baku di gudang yang dinyatakan dalam persentase dari nilai persediaan rata-rata dalam satuan mata uang yang disebut dengan carrying cost atau storage cost atau holding cost.

PxI = besarnya biaya penyimpanan bahan baku per unit.

Perhitungan EOQ dapat dilakukan dengan rumus sebagai berikut:

$$
\mathrm{EOQ}=\sqrt{ } 2 \mathrm{DS} / \mathrm{h}
$$

Keterangan:

$\mathrm{S}=$ Biaya pemesanan per pesanan

$\mathrm{D}=$ Pemakaian bahan periode waktu

$\mathrm{H}=$ Biaya penyimpanan per unit per tahun

Dari uraian rumus - rumus di atas penelitian ini menggunakan rumus yang kedua, karena data yang di dapat dalam perusahaan.

Perhitungan ROP dapat dilakukan dengan rumus sebagai berikut:

$$
\mathrm{ROP}=\mathrm{d} \times 1
$$

Keterangan:

$\mathrm{d}=$ Penggunaan selama lead time

1 = Safety stock 


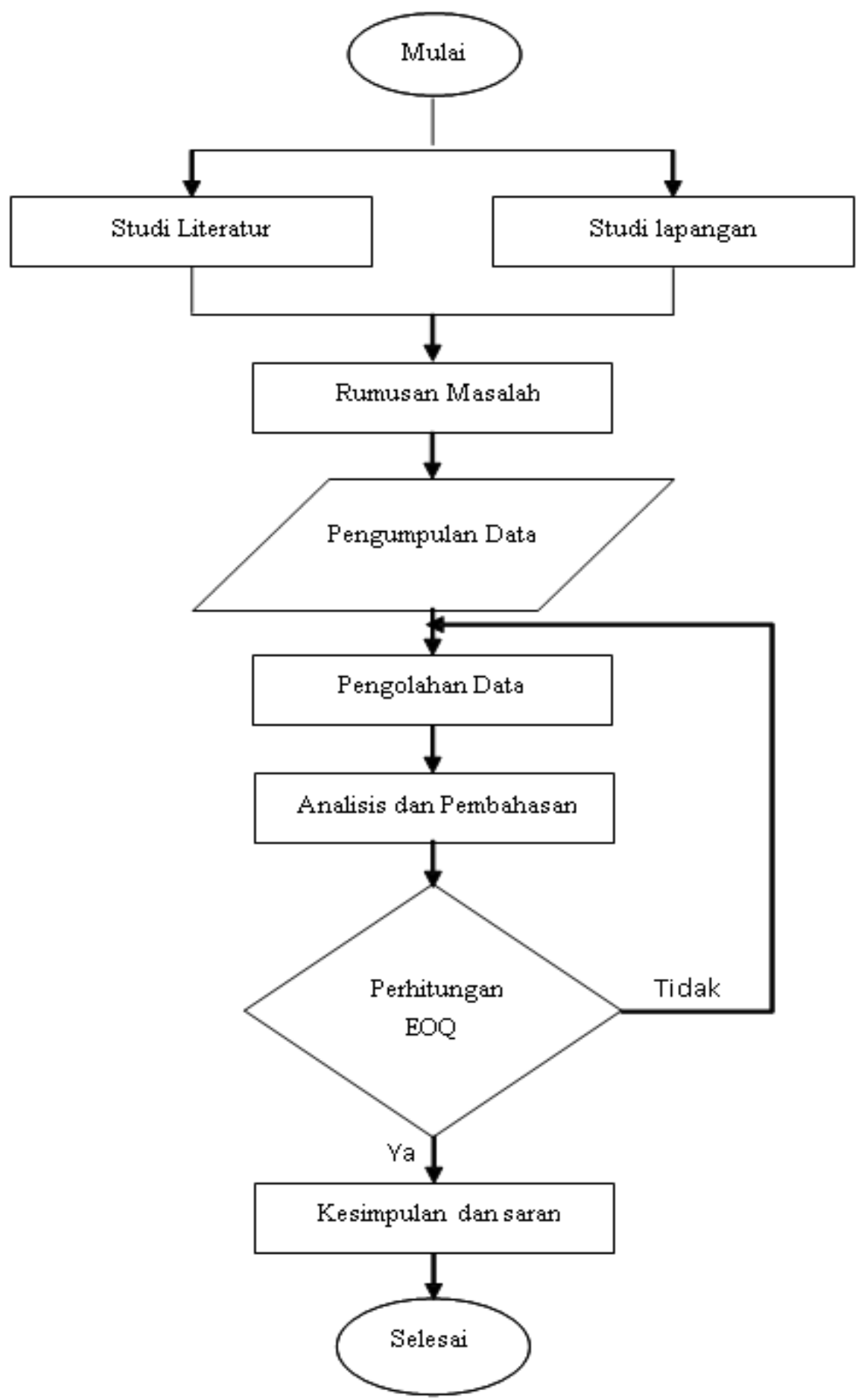

Gambar 1. Diagram Alir Penelitian

\section{HASIL PENELITIAN}

A Data penggunaan bahan baku pada Fuji Seat (logam)

Berdasarkan Tabel I terlihat bahwa pemakaian bahan baku dari tahun 2016 - 2019 .
Total pemakaian bahan baku terendah pada tahun 2016 sebesar 1231,390 pcs, sedangkan total pemakaian bahan baku tertinggi pada tahun 2019 sebesar 1285,286 pcs. 
Jurnal Media

Teknik dan

Sistem Industri

TABEL I

PEMAKAIAN BAHAN BAKU FUJI SEAT LOGAM (PCS)

\begin{tabular}{ccccc}
\hline Bulan/Tahun & 2016 & 2017 & 2018 & 2019 \\
\hline Januari & 90,000 & 90,000 & 91,450 & 93,000 \\
Februari & 120,500 & 121,550 & 122,676 & 122,740 \\
Maret & 151,880 & 151,880 & 153,450 & 153,450 \\
April & 95,550 & 96,800 & 101,330 & 103,440 \\
Mei & 130,990 & 131,400 & 132,445 & 133,100 \\
Juni & 75,600 & 75,600 & 79,540 & 79,540 \\
Juli & 82,150 & 82,200 & 85,000 & 86,827 \\
Agustus & 93,000 & 93,000 & 96,500 & 96,500 \\
September & 96,300 & 101,500 & 103,500 & 105,139 \\
Oktober & 101,600 & 101,500 & 111,500 & 111,500 \\
November & 105,050 & 104,500 & 111,050 & 111,050 \\
Desember & 88,770 & 85,128 & 89,000 & 89,000 \\
& 1231,390 & 1235,158 & 1277,441 & 1285,286 \\
\hline
\end{tabular}

Laporan Pencapaian Delivery

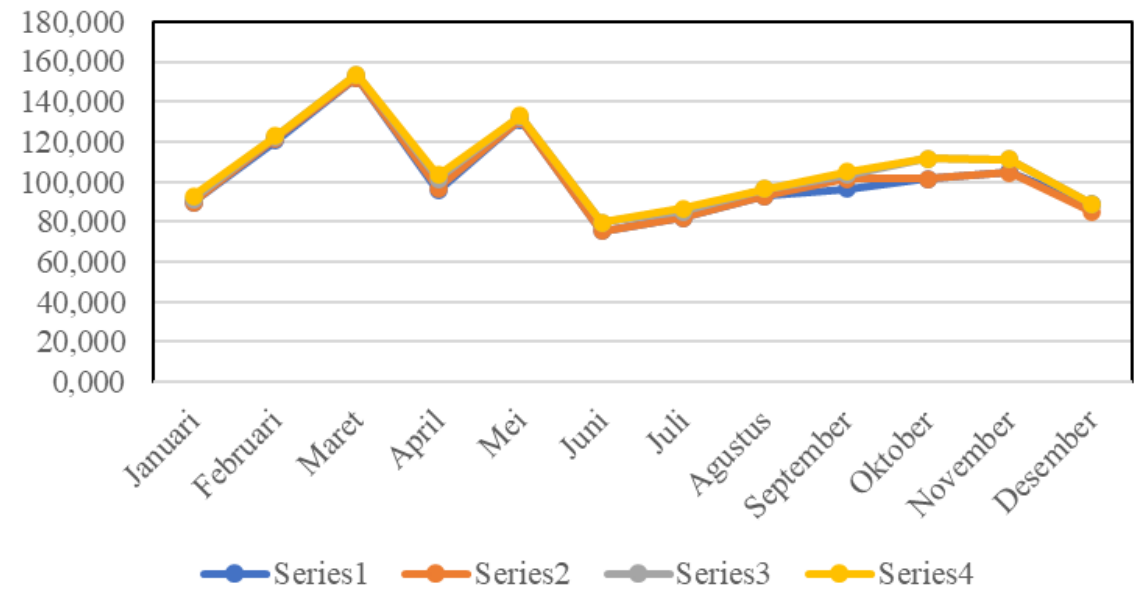

Gambar 2. Grafik pemakaian bahan baku

Dari gambar grafik diatas titik tertinggi pembelian bahan baku yaitu pada bulan Maret, titik terendah pembelian bahan baku yaitu bulan Juli.

\section{B Data Mengenai Harga Bahan Baku}

TABEL II

HARGA BAHAN BAKU PER PCS PERIODE 2016-2019

\begin{tabular}{cc}
\hline Tahun & Harga Bahan Baku (Rp) \\
\hline 2016 & 195,000 \\
2017 & 195,000 \\
2018 & 220,000 \\
2019 & 220,000 \\
\hline
\end{tabular}

Harga bahan baku yang ditetapkan PT. Tri Jaya Teknik Karawang pada produk fuji seat (logam) per pcs pada periode 2016 dan 2017 sebesar Rp. 195,000. Sedangkan pada periode 2018 dan 2019 sebesar Rp. 220,000. Setiap dua periode sekali meningkat sebesar Rp. 25,000.

\section{Data Biaya Bahan Baku}

Data biaya bahan baku di dapat dengan mengalikan data pemakaian bahan baku setiap periode dengan harga bahan baku tiap periode. 
TABEL III

BIAYA BAHAN BAKU PER PCS PERIODE 2016-2019

\begin{tabular}{cc}
\hline Tahun & Harga Bahan Baku (Rp) \\
\hline 2016 & 240121,050 \\
2017 & 240855,810 \\
2018 & 281037,020 \\
2019 & 282762,920 \\
$\Sigma$ & 1044776,800
\end{tabular}

Biaya bahan baku yang dibutuhkan selama empat periode yaitu sebesar Rp. 1044776,800. TABEL IV

LEAD TIME DAN SAFETY STOCK PERIODE 2016-2019

\begin{tabular}{ccc}
\hline Tahun & Lead Time (hari) & Safety Stock $(\mathrm{pcs})$ \\
\hline 2016 & 3 & 5590 \\
2017 & 3 & 6320 \\
2018 & 3 & 5265 \\
2019 & 3 & 6673 \\
\hline
\end{tabular}

\section{PEMBAHASAN}

Biaya penyimpanan bahan baku di tetapkan oleh pihak PT. Tri Jaya Teknik Karawang sebesar 2,5\% dari harga per pcs, nilai tersebut digunakan untuk keperluan pengadaan dan perbaikan alat serta perlengkapan di gudang penyimpanan. Apabila tidak terjadi kerusakan maka biaya tersebut dialokasikan ke pengelola gudang dalam bulan tersebut. Besarnya biaya Simpan adalah:

$$
\begin{aligned}
& =2,5 \% \text { x Rp. } 195.000,00 \\
& =\text { Rp 4.875,00 (Tahun } 2016 \text { dan 2017) } \\
& =2,5 \% \times \text { Rp. } 220.000,00 \\
& =\text { Rp 5.500,00 (Tahun } 2018 \text { dan 2019) }
\end{aligned}
$$

Sedangkan biaya pemesanan yang terdiri dari harga barang dan biaya pengiriman ditetapkan pihak PT. Tri Jaya Teknik Karawang sebesar Rp 100.000,00. Biaya ini meliputi biaya administrasi dan transportasi. Biaya administrasi yaitu gaji eksekutif dan pendukung lainnya,serta pajak yang berkaitan dengan perusahaan. Biaya transportasi pengiriman yaitu jarak yang ditempuh serta berat produk yang dipesan.

Selanjutnya menghitung ROP untuk menentukan berapa waktu perusahaan harus melakukan pemesanan, sehingga datangnya pesanan tersebut tepat dengan habisnya bahan.

\section{1) ROP pada Tahun 2016}

Penggunaan selama 1 tahun $=1231,390$

Penggunaan selama 1 hari $=1231.390 / 360=$ 3,42 pcs.
Penggunaan selama lead time $=3 \times 3,4=10,26$ pcs

$\mathrm{ROP}=10,26+3181=3191,26=3191 \mathrm{pcs}$

Jumlah unit pesanan optimal per tahun = $1231 / 7.107=173,2 \mathrm{pcs}$

Pemesanan per hari $=365 / 173,2=2,1=2$ hari

2) ROP pada Tahun 2017

Penggunaan selama 1 tahun $=1235,158$

Penggunaan selama 1 hari $=1235,158 / 360=$ 3,43 pcs.

Penggunaan selama lead time $=3 \times 3,43=10,29$

pcs

$\mathrm{ROP}=10,29+3190=3200,29=3.200 \mathrm{pcs}$

Jumlah unit pesanan optimal per tahun = $1235,158 / 7.118=173,5 \mathrm{pcs}$

Pemesanan per hari $=365 / 173,5=2,1=2$ hari

3) ROP pada Tahun 2018

Penggunaan selama 1 tahun $=1277,441$

Penggunaan selama 1 hari $=1277,441 / 360=$ 3,54 pcs.

Penggunaan selama lead time $=3 \times 3,54=10,64$ pcs

$\mathrm{ROP}=10,64+3300=3300,64=3.330 \mathrm{pcs}$

Jumlah unit pesanan optimal per tahun = $1277,441 / 6,815=187,4$ pcs

Pemesanan per hari $=365 / 187,4=1,9=2$ hari

4) ROP pada Tahun 2019

Penggunaan selama 1 tahun $=1285,286$

Penggunaan selama 1 hari $=1285,286 / 360=$ 3,57 pcs.

Penggunaan selama lead time $=3 \times 3,54=10,71$ pcs

$\mathrm{ROP}=10,71+3320=3330,71=3.330 \mathrm{pcs}$

Jumlah unit pesanan optimal per tahun = $1285,286 / 6,815=188,01$ pcs

Pemesanan per hari $=365 / 188,01=1,9=2$ hari

Tahapan selanjutnya yaitu mengolah data dengan menggunakan model Economic Order Quantity (EOQ) dan menentukan periode yang paling ekonomis.

1) Pembelian paling Ekonomis untuk Tahun 2016

$$
\begin{aligned}
\text { EOQ } & =\frac{\sqrt{2 S D}}{h} \\
& =\frac{\sqrt{2(1231,390)(100,000)}}{4,875} \\
& =7,107.64 \mathrm{Pcs}
\end{aligned}
$$

Frekuensi pembelian yang paling ekonomis pada

Tahun 2016 adalah:

$\mathrm{F}=1231,390 / 7,107.64$

$\mathrm{F}=173.24$ kali.

2) Pembelian paling Ekonomis untuk Tahun 2017 


$$
\begin{aligned}
\text { EOQ } & =\frac{\sqrt{2 S D}}{h} \\
& =\frac{\sqrt{2(1235,158)(100,000)}}{4,875} \\
& =7,118.5 \text { Pcs }
\end{aligned}
$$

Frekuensi pembelian yang paling ekonomis pada Tahun 2017 adalah:

$\mathrm{F}=1235,158 / 7,118.5$

$\mathrm{F}=173.51$ kali.

3) Pembelian paling Ekonomis untuk Tahun 2018

$$
\begin{aligned}
\text { EOQ } & =\frac{\sqrt{2 S D}}{h} \\
& =\frac{\sqrt{2(1277,441)(100,000)}}{5,500} \\
& =6,815.5 \mathrm{Pcs}
\end{aligned}
$$

Frekuensi pembelian yang paling ekonomis pada Tahun 2018 adalah:

$\mathrm{F}=1277,441 / 6,815.5$

$\mathrm{F}=187.4$ kali.

4) Pembelian paling Ekonomis untuk Tahun 2019 $\mathrm{EOQ}=\frac{\sqrt{2 S D}}{h}$

$$
\begin{aligned}
& =\frac{\sqrt{2(1285,286)(100,000)}}{5,500} \\
& =6,836.4 \mathrm{Pcs}
\end{aligned}
$$

Frekuensi pembelian yang paling ekonomis pada Tahun 2019 adalah:

$$
\mathrm{F}=1285,286 / 6,836.4
$$$$
\mathrm{F}=188 \text { kali. }
$$

Berdasarkan data pada tahun 2018, pembelian paling ekonomis dengan menggunakan model EOQ didapat sebesar 6,815.5 Pcs dengan pembelian sebanyak 187 kali dalam satu tahun. Sedangkan perusahaan mengalami peningkatan frekuensi pembelian pada tahun 2019 .

\section{KESIMPULAN}

Berdasarkan hasil penelitian yang dilakukan, maka dapat diambil kesimpulan sebagai berikut:

1. Hasil rekapitulasi hasil perhitungan EOQ dan Frekuensi Pembelian dapat dilihat pada tabel IV di bawah ini.

TABEL IV

REKAPITUlasi HASIL PERHITUNGAN EOQ DAN FREKUENSI PEMBELIAN PERIODE 2016-2019

\begin{tabular}{ccccc}
\hline Keterangan & 2016 & 2017 & 2018 & 2019 \\
\hline Pemakaian/Bulan(pcs) & 1231,39 & 1235,158 & 1277,441 & 1285,286 \\
Biaya Pesan (Rp) & 100,000 & 100,000 & 100,000 & 100,000 \\
Penyimpanan (Rp) & 4,875 & 4,875 & 55,000 & 55,000 \\
ROP (pcs) & 3191 & 3200 & 3310 & 3330 \\
EOQ (pcs) & $7,107.64$ & $7,118.5$ & $6,815.5$ & $6,836.4$ \\
Frekuensi (pcs) & 173,24 & 173.51 & 187.4 & 188 \\
\hline
\end{tabular}

Dari tabel IV diketahui pemakaian, biaya pesan, biaya simpan, pembelian paling ekonomis berdasarkan model Economic Order Revised Edition of Finance Management Quantity (EOQ) dan frekuensi pembelian setiap tahunnya selama periode 2016-2019.

2. Usulan perbaikan untuk perusahaan berdasarkan perhitungan EOQ (Economic Order Quantity) jumlah bahan baku yang paling ekonomis dengan menggunakan model EOQ didapat sebesar 6,815.5 Pcs dengan pembelian sebanyak 187 kali dalam satu tahun yaitu pada tahun 2018.

\section{REFERENSI}

[1] A. Ahyari, "Manajemen Produksi, Pengendalian Produksi.," Yogyakarta: BPEE., vol. 4, no. 2. 2006

[2] M. K. P. Taska and D. T. Yulianti, "Sistem Informasi Manajemen Obat RSUD Cideres dengan Penerapan Metode EOQ dan ROP," J. Strateg., vol. 2, no. November, pp. 466-475, 2020.
[3] S. Hadi, "Metodologi Research," Universitas Gajah Madha. 2014

[4] K. Hidayat, J. Efendi, and R. Faridz, "Analisis Pengendalian Persediaan Bahan Baku Kerupuk Mentah Potato Dan Kentang Keriting Menggunakan Metode Economic Order Quantity (EOQ)," Performa Media Ilm. Tek. Ind., vol. 18, no. 2, pp. 125-134, 2020, doi: 10.20961/performa.18.2.35418.

[5] A. Amrillah, Z. ZA, and M. NP, "ANALISIS METODE ECONOMIC ORDER QUANTITY (EOQ) SEBAGAI DASAR PENGENDALIAN PERSEDIAAN BAHAN BAKU PEMBANTU (Studi Pada PG. Ngadirejo Kediri - PT. Perkebunan Nusantara X)," J. Adm. Bisnis S1 Univ. Brawijaya, vol. 33, no. 1, pp. 35-42, 2016.

[6] D. A. Widayati, T. Lestari, and Mahsina, "Analisis Implementasi Sistem Informasi Akuntansi Penerimaan dan Pengeluaran Kas Pada PERUM BULOG Surabaya Utara," J. Ekon. Akunt. Equity. ISSN 2460-7762. Univ. Bhayangkara Surabaya., vol. Vol. 1, no. No.1, 2015.

[7] E. Suryani, "Analisis Pengendalian Persediaan Produk Dengan Metode EOQ Menggunakan Algoritma Genetika untuk Mengefisiensikan Biaya Persediaan," vol. 1, 2012.

[8] A. Taufiq and A. Slamet, "Pengendalian Persediaan 
Bahan Baku dengan Metode Economic Order Quantity (EOQ) pada Salsa Bakery Jepara," Manag. Anal. J., vol. 3, no. 1, pp. 1-6, 2014, doi: 10.15294/maj.v3i1.3355.

[9] L. Syamsuddin, "Manajemen Keuangan Perusahaan Konsep Aplikasi dalam: Perencanaan, Pengawasan, dan Pengembaian Keputusan,” J. Adm. bisnis, 2011

[10] M. Tuerah, "Analisis Pengendalian Persediaan Bahan Baku Ikan Tuna pada CV. Golden Kk," J. Ris. Ekon. Manajemen, Bisnis dan Akunt., vol. 2, no. 4, 2014. 